In 1824 two other surgeons who had been students at the hospital were sent out by the Company to found eye hospitals in Bombay and Calcutta. Very many Indan medical men and women have received their training at Moorfields; the supply of women doctors is particularly valuable to India, on account of the large numbers of women precluded from receiving assistance from men.

The appeal which is being issued in this country, whilst stating the lines on which it is hoped that future progress will be made, dwells more particularly on the great and pressing needs with which the Committee of the Hospital are at present faced. These have been occasioned by the enormously increased cost of every commodity, and by the rise of salaries. As the appeal pointedly says, the prevention and cure of blindness by means of voluntary contributions is surely better than doles (from rates and taxes) to those who have irretrievably lost their sight.

\title{
ABSTRACTS
}

\section{I.-MIGRAINE AND GLAUCOMA}

Lamb, R. S. (Washington).-Is migraine a forerunner of glaucoma? Aninals of Ophthalmology, October, 1915, and Trans. Colorado Congress, I9I 5.

Lamb has had under his observation a large number of cases of migraine, and has made the following observations on them: (1) In all, the ocular tension was found to be up; sometimes slightly, sometimes markedly so ; (2) in every one in which the headache was associated with intense photophobia, there was evidence of chorio-retinitis, especially in the central region; (3) the exciting cause of the attacks was frequently an error of refraction (hypermetropic astigmatism predominating), and in such cases more or less severe chorio-retinitis was always found; (4) the exciting causes of migraine, viz., nerve exhaustion and nerve shock, are also those of congestive glaucoma; (5) both diseases are apt to occur in families;' (6) 'both are associated with gout; (7) he has been unable to find common features in the fields of vision of the two diseases; but (8) clinically there are points of resemblance, for he has "been able to ascertain on which side the pain was in the habit of occurring by observing that the pupil of that side was more dilated, and the anterior chamber was shallow as compared with that of the other eye." There was also "a slight difference in the colour of 
the iris . . . and definite, though slight ciliary congestion." Cases are given, and the treatment adopted is there indicated. A careful correction of errors of refraction, under a cycloplegic, the usual constitutional treatment, and the instillation of a weak miotic solution are its principal features. The paper is thoughtful, interesting, and stimulating; it constitutes a move off the beaten tract of stereotyped therapeutics and, as such, it deserves the sympathetic and careful consideration of all who are engaged, for the benefit of their patients, in the study of clinical ophthalmology. On the face of his evidence Lamb would appear to have made a case for watching of the tension of the eyes in all cases of migraine, and of exhibiting miotics, whenever that tension is raised. It may also be, as he suggests, that migraine cases later run on into glaucoma; it is to be regretted that he did not give more definite evidence on this head. It is, however, another and quite different proposition to maintain that migraine is "a forerunner of glaucoma." Lamb quotes Priestley Smith's definition of glaucoma. In his book on the subject, Priestley Smith defined glaucoma as " an excess of pressure within the eye, plus the causes and the consequences of that excess." Of recent years there has been a disposition, and we think a well-founded disposition, to believe that all excess of intra-ocular pressure is not necessarily glaucoma. A healthy eye can compensate for accidental increases of pressure that occur within it. It is the predisposed eye which falls a victim to glaucoma, under the strain of altered vascular conditions of the organ, or of the system generally, or of both. If Lamb's observations are confirmed, it will presumably be proved that migraine, which we regard as being central in origin, is associated with a grave alteration of the vascular condition in the eye itself, and that this alteration is of such a nature as to lead to the obstruction of the exit of venous blood from the uveal tract, thereby shallowing the chamber and dilating the pupil. We are justified in believing that these phenomena are the result of increased intraocular pressure, and that, provided the eye is in a condition predisposing it to glaucoma, a pathological increase of tension will take place. It is doubtful if we can go beyond this. The reviewer offers these observations with some little hesitation, for he feels himself indebted to Dr. Lamb for a paper which provokes thought, and suggests no small clinical possibilities. R. H. ElLIOT.

\section{II.-SWIMMING BATH CONJUNCTIVITIS}

Comberg, W. - On swimming bath conjunctivitis. (Ueber Badkonjunktivitis.) Zeitschr. f. Augenheilk., Vol. XLIV, Part i-ii, 1920. 
Comberg has had the opportunity of examining cases of swimming bath conjunctivitis, which during the autumn of 1919 assumed an almost epidemic form in Berlin. This condition was described by Schultz in 1899, who considered it to be a form of trachoma. Fehr, in 1900, published an article upon the same disease, and pointed out that, although in many respects similar to trachoma, it healed more rapidly, and that the upper lid improved sooner than the lower, whereas in real trachoma the reverse holds. Also, that complete cure with minimal, if any, scarring of the lids, was the rule. All Comberg's cases came from the same bath, and that the last built and best appointed in Berlin. The incubation period of the disease appeared to be ten days. It was characterized by an acute oederna of the conjunctiva, sometimes associated with swelling of the lids and enlargement of the preauricular, glands. The skin of the lids was tense, red, and hot in these severe cases. Ptosis was generally noted. The secretion was but slightly purulent. The lids were generally stuck together in the morning.

The cases were treated with protargol daily and were touched three times a week with the copper alum pencil. Some of the cases were well in two or three weeks, but in others two to three months' treatment was necessary. No scars were left in the conjunctiva, the tarsus was not thickened, and pannus was never present.

Comberg considers that bath conjunctivitis is not trachoma. No organisms could be detected in the secretion, but in some cases inclusion bodies were seen in the cells of the conjunctiva. A piece of the inflamed conjunctiva was excised and examined. The condition found is fully described in the text; it was not similar to trachoma. Comberg inspected the bath to which the infection was traced. The male bath, more used than the female bath, contained eight times as many.organisms as the female, and all the patients were males. The bath attendants had normal eyes, showing no trace of conjunctivitis. The cubicles were clean, and were washed daily with sublimate solution. The bathers brought their own towels and costumes. It was suggested that the water should be chlorinated, and that steps should be taken to previent infected persons from using the bath.

T. HARRISON BUTLER. 


\section{III.-ULTRA-VIOLET LIGHT IN DISEASES OF THE CORNEA}

\section{Birch-Hirschfeld (Leipzig).-Upon the treatment of inflammatory corneal diseases, and especially serpent ulcer, with ultra- violet light. (Zur Behandlung entzündlicher Hornhauter- krankungen besonders des Ulcus serpens mit ultravioletten Licht.) Zeitschr.f. Augenheilk., Vol. XLIV, Part i-ii.}

Birch-Hirschfeld has carried out much experimental work in connection with the harmful effect of ultra-violet light upon the eye, and has confirmed the opinion that it may be responsible for conjunctivitis, retinitis, cataract, and keratitis. On the other hand, the same rays have been useful in the treatment of certain skin diseases and infections of the mucous membrane, and it seemed to him that it was worth while to investigate their action upon the cornea, and especially upon serpent ulcer. Twelve years ago Hertel, using the Cadmium zinc lamp, which furnishes intense ultra-violet rays, obtained good results in this disease. Twenty-six cases were healed with good vision, but in 13 cases out of 47 the light failed to inhibit the spread of the ulcer. Chotzen and Kuznitsky.treated chronic keratitis with rays from a mercury-vapour lamp with a quartz attachment, and stated that they obtained good results when all other treatment had failed. Hertel's work made the author wish to take up the light treatment of corneal ulcers, but the success of optochin, which was being tried at Leipzig, postponed the attempt. Experience showed that optochin had been over-rated, and that many ulcers had to be cauterized and treated by section. Out of 62 cases of pneumococcal ulcer treated with optochin at Königsberg; only 13 were cured. Other surgeons, including Wessely, Gruter, Bluhm, Dubois, Gradle, and Schnyder have spoken unfavourably of optochin. These disappointments opened the way for a trial of ultra-violet light. Not having a Cadmium zinc lamp the author contented himself with a small arc-lamp in front of which he fitted a uviol glass and a quartz lens of 20 dioptres. The surgeon held a second quartz lens between his thumb and index finger further to concentrate the rays upon the advancing edge of the ulcer. : Most of the luminous rays are absorbed by the uviol glass, and no discomfort was caused by glare or heat. The experiment was not crowned with success, especially with respect to pneumococcal ulcers, which continued to spread. Accordingly the absorptive power for ultra-violet rays was exalted by sensitizing the cornea with a 2 per cent. solution of fluorescein. Forty-three pneumococcal ulcers taken consecutively without selection were treated in this manner. In 40 the treatment was carried out to its conclusion with the result that only 6 cases failed to receive benefit. These were 
severe and neglected cases. In the remainder good results were obtained. In many of the severe examples improvement was evident after a few irradiations of from 3 to 5 minutes once or twice a day. No trace of any ophthalmia electrica was noted, because the short wave-length light was concentrated upon the ulcer and did not fall upon other tissues. In 33 cases treated by light alone the functional result was good. The number of applications called for was very varied. In 12 cases 5-7 days sufficed, whereas in one case the irradiation was continued for 27 days. Experience• alone can decide the necessary time and frequence of the light application. The apparatus is simple and comparatively inexpensive. Koepp's lamp appears to be the best for the purpose. The author has grave doubts as to the value of irradiation for trachoma.

T. HARRison BUtLER.

\section{IV.-TEMPORARY PARALYSIS OF THE LIDS IN CATARACT OPERATIONS}

Villard, H.-Temporary paralysis of the lids in cataract operations. (Paralysie temporaire des paupières dans l'opération de la cataracte.) Bulletins de la Société française d'Ophtalmologie, 1919.

Villard, in order to eliminate all risk of "squeezing" in nervous patients and thus prevent loss of vitreous, makes a subcutaneous injection of novocain $(1 / 100)$ and cocain $(1 / 150)$ over the fibres of the facial nerve as they spread out to supply the orbicularis muscle. He uses a syringe holding about $5 \mathrm{cc}$. with a needle about $3-4 \mathrm{~cm}$. in length. Three injections are made, the first vertical a little above and behind the eyebrow deeply into the malar region, the second from where the point of the needle has penetrated horizontally towards the upper part of the ala of the nose, $1 \mathrm{~cm}$. below the infra-orbital margin. By these two injections he has practically encircled the outer and lower part of the orbital margin and thus caught all the filaments of the facial nerve. The third injection is made at the external commissure and is directed outwards towards the parotid. About two cc. of fluid are used for each injection.

After 2-5 minutes the lids can be separated without the smallest resistance on the patient's part, and when the effect has reached its maximum the eye cannot be closed by voluntary effort. The duration of the paralysis is from ten to fifteen minutes.

In order to avert any toxic action a strong cup of coffee is taken immediately before the injections are commenced.

The disadvantage is that the patient is unable to close the eye 
after operation; the gentle pressure of a dressing will, however, get over this difficulty.

The great advantage is the perfect calmness which is produced and which does away with the necessity for an assistant.

C. Killick.

\section{V.-WOUNDS OF THE CILIARY REGION}

Lagrange, Professor (Bordeaux).-The gravity of wounds of the eye according to whether the ciliary region is or is not involved; the treatment of such wounds. (Des plaies de l'oeil, leur gravité selon que la région ciliaire est ou non intéressée ; leur traitement.) Rev. gén. d'Ophtal., February, 1920.

This article is short, but of great importance. Lagrange indicates that a more elaborate publication is in contemplation. The author's object, very largely as the result of extensive war experience, is to formulate certain rules for the guidance especially of those whose personal experience has not. yet been sufficiently extensive to yield them a firm opinion on the subjects of prognosis and treatment of ocular injuries. His experience has convinced him that wounds of the ciliary body, other things being equal, are much more dangerous than wounds of other parts of the globe. This is in conformity with the views of such classical writers as Arlt, Röhmer, and Sichel, as opposed to those who hold the opinion that the danger depends upon the infective agent and not upon the situation within the eyeball. Lagrange, indeed, points out that even in the absence of foreign body, and without infection, a wound of the ciliary body may be quite destructive of the eyeball, the nutrition of which is thereby completely upset.

Lagrange classifies the wounds of the eyeball as follows :

(1) Wounds of the ciliary region-(a) with foreign body in the eye, (b) without foreign body in the eye.

(2) Wounds outside of the ciliary region-(a) with foreign body in the eye, $(b)$ without foreign body.

His experience of these groups may be summarized :

(1) (a) 18 cases. 3 cases of sympathetic ophthalmitis. 15 cases in which the end was either enucleation or phthisis bulbi. So that a wound of the eye in the ciliary region with foreign body, whether that foreign body remains in the ciliary region or lodges elsewhere in the eye, is fatal to the eye. (The author does not seem to mention whether this absolutely fatal prognosis is in any way modified by removal of the foreign body, but the reviewer assumes that the author means to state that penetration of the ciliary region by a 
foreign body is fatal to the eye whether the foreign body is removed or not).

(1) (b) Again 18 cases. 2 cases of sympathetic ophthalmitis. A useful eye retained in 7 cases. The remainder lost.

(2) (a) 32 cases. Only 1 enucleation. The remainder relatively satisfactory. V.A. from $8 / 10$ to $1 / 100$. Magnetic foreign body extracted 5 times. 12 times the nòn-magnetic foreign body (generally copper) remained in the eye without causing trouble necessitating enucleation.

(2) (b) 15 cases. Enucleation in 2 cases. 10 cases with acuity from $10 / 10$ to $1 / 50$. 3 cases with normal tension but no vision.

The author calls special attention to the fact that in the second group of cases there was no sympathetic disease. Admitting the existence of a special infective agent, it is evident that this organism requires a special medium for its multiplication, and that the ciliary body, owing to its complex structure and the richness of its nerve plexus, offers the necessary favourable soil.

Wounds of the eyeball are thus to be arranged in the following decreasing order of gravity :

(1) Wounds of the ciliary body with foreign body.

(2) " ", ", ", without ," ,

(3) Wounds of the eye outside the ciliary region; with f.b.

(4) ", ", " , " " without f.b.

The statistics show that it may be better that there should be a wound with foreign body in the posterior hemisphere than a wound in the ciliary region without foreign body. The author confesses that, although admittedly sympathetic disease was very uncommon in the late war, he is nevertheless very much afraid of it, since he personally saw a number of cases. His "rules of conduct" have also been influenced by his opinion that a well-fitted artificial eye is better than an unsightly damaged one.

The author's "rules of conduct," which have been drawn up for the use of those who have had insufficient personal experience to come to a firm conclusion as to the line of treatment best to be pursued in these difficult cases, may perhaps be omitted here. They are on the usual lines, and are as clear as such rules-made to be broken on occasion by every man of experience-can be.

ERNEST THOMSON.

\section{VI.-DETACHMENT OF THE RETINA}

Gonin, J.-The anatomical causes of retinal detachment. Ann. d'Ocul., Vol. CLVI, May, 1919. 
Gonin has been able to make a collection of some hundreds of half eyeballs in gelatin, and finds on examining them that he can put them into four groups, according to the different mechanisms at work. Thus, displacement of retina, amotio retinae, can come from raising up of retina, sublatio retinae, by vis a tergo under direct pressure of choroid itself displaced or thickened by tumour, or rather by the intermediation of an effusion of liquid between choroid and retina; from attraction of retina, attractio retinae, by a force acting on its anterior surface, either by direct action of vitreous in a state of pathological retraction, or by the cicatricial retraction of adhesions created between retina and a wound of anterior segment of eye ; from distension of retina, distensio retinae, followed by tearing or by separation from one of its insertions; from depression of retina, depressio retinae, a phenomenon exactly opposite to the last, and manifesting itself by a folding of the nervous membrane, consecutive to a sudden or slow diminution of the volume of the eyeball.

The first group includes all degrees of detachment from the complete, as seen in the expulsive haemorrhage cases, to the slighter varieties. Some small choroidal tumours have a lot of fluid exudate, other larger tumours may have little or none. Sometimes choroid remains in place and a haemorrhage or exudate lifts off the retina, a serous exudate occurring from some inflammatory cause in the neighbourhood, e.g., scleritis, acute choroiditis, abscess of cornea, suppurative cyclitis, or from some circulatory trouble such as orbital tumour or albuminuric retinitis. Haemorrhages are sometimes spontaneous as in diabetes, arterio-sclerosis, or they have a traumatic origin from contusion or perforation. Folds of retina are here not numerous, while the retro-retinal exudate differs in consistence, colour and chemical composition from the liquid which fills the hyaloid space, but in some cases after violent and prolonged inflammation there is an apparent identity, as in certain metastatic suppuration cases. His collection has 90 examples of this vis a tergo group, but if one takes away those where the retina remains in contact with the choroid itself raised up, and those where the retro-retinal exudate has been but an epiphenomenon of the development of the tumour, there remain but 10 examples where the detachment can be due to a primary exudate of the choroid. Hence, Gonin thinks operations for removal of the fluid are not likely to be of much use.

In the attraction group are quite a number in which the vitreous, by reason of diverse alterations, e.g., haemorrhagic infiltrate, chronic inflammation or suppuration is not only detached from the retina, but even retracted right up to the equator without the retina having anywhere left its normal situation. There must be adhesions between vitreous and retina before retraction of the 
former displaces the latter. These adhesions may be old or produced just before the retraction of the hyaloid. In the presence of a total suppuration of the vitreous, the welding is often complete to the point that one can only with great care distinguish the vitreous mass from the retina and that it detaches itself from the choroid in all its extent. The funnel shape is often present, but in many of Gonin's cases the retina appears to have torn away from the disc, when vitreous and retina together form a yellowish mass on the back of lens or ciliary body. Welding may be local and not general and thus allow local detachments to occur, and in these the tears, emphasized by Leber, sometimes appear valve shaped and sometimes quite obviously punched out, especially about the ora serrata. The hyaloid fluid at once gets access to the retro-retinal space so that in recent cases the two spaces have similar fluid, but in older specimens in which the communications may have become shut off the fluids are different, the retro-retinal space showing relics of haemorrhage or cholesterin, while the retina, reduced to a cord, encloses the relics of the vitreous. Attractions independent of the vitreous body are usually due to perforating injury at the ciliary region, where the greater haemorrhage may lead to greater retraction. Where the track of a foreign body involves retina, choroid, and sclera, the whole globe tends to become deformed. In 125 of Gonin's cases attraction was the cause, i.e., 40 per cent. of the cases of detachment. Of these about ten were idiopathic, the others followed traumata: retraction of vitreous and cicatricial retraction of a perforating wound were about equally responsible with each other for the detachment.

The third, or distension, group is best seen in myopia, where the retina is far from being so inextensible as one supposes, especially in the presence of a slow and continuous distension where it shows a great adaptability - it becomes very much thinned out but is not detached. His specimens show such in high myopia and glaucomatous macrophthalmia and there is actually one with a marked lateral staphyloma where the retina is in place over the distended portion, while on the opposite side it is detached without any tear. Contusions must be sudden and violent to cause detachment with or without scleral rupture and here partial or complete tears of retina may occur at ora serrata or at disc, usually the former. In his series Gonin can find only ten cases where retinal rupture from distension can reasonably be admitted.

The fourth, or depression, group is the counterpart of the previous group and includes cases where the sclera becomes reduced in extent by brisk depression with copious loss of vitreous or even slow atrophy, so that the retina becomes much folded, although not necessarily accompanied by compensatory choroidal exudate.

The paper has 18 figures in the text. 
Gonin admits the existence of mixed and intermediate forms, but thinks his classification may be quite useful macroscopically. $\mathrm{He}$ hopes to discuss in a further article how such groupings can be made clinically, and also the methods of treatment suitable to each form.

W. C. SOUTER.

\section{VII.-EPITHELIOMA OF THE BULBAR CONJUNCTIVA}

\section{Cosmettatos, G. F. (Athens.)-Recurrent epithelioma of the} bulbar conjunctiva-death by metastasis. Ann. d'Ocul., Vol. CLV, January, 1918 (with three figures).

Cosmettatos brings forward the present case because of the peculiar histological features and of the rarity of metastasis in these cases. In or about September, 1908, the man had had an apparently trivial injury to the right eye with a chip of wood; one year later there appeared on the ocular conjunctiva towards the outer canthus a small excrescence growing slowly so that after a year it was the size of a coffee bean; at this time it was extirpated. The eye never became quite quiet, and after two months the tumour recurred at the same place and became as big as a small almond. This was again operated on, but recurrence having taken place the patient came to Cosmettatos in May, 1911, the man being then 30 years of age. The tumour mass appeared to be free from ocular conjunctiva and to arise from episclera, painless, sharply circumscribed : vision normal ; other eye normal. Complete extir pation of tumour, cauterization of base, suture, good recovery, went home "cured." The tumour sections showed a connective tissue epvelope with processes passing inwards, enclosing epithelial masses. The' cells were grouped round the papillary axis, basal cylindrical cells, then a layer of polygonal cells, finally flattened epithelial cells, on the surface of the tumour. The irregular aspect of the epithelial masses, the abundance of abnormal karyokineses, and the rapid recurrence of the tumour, all pointed to malignancy, and in April, 1912, he came back with a large tumour coming out between the lids, frankly epitheliomatous now, size of chestnut, colour red, surface bleeding, lids free except that the palpebral conjunctiva far above was apparently invaded. Enucleation of eye and removal of infiltrated conjunctiva, thermo-cautery, uneventful recovery, home after 15 days. No gross change seen in the opened globe, but sections showed invasion of corneal lamellae and round the canal of Schlemm, while the peculiar irregularity of the disposition of the karyokinetic figures was quite a feature. Normally, these figures have their long axes at right angles to the basal membrane of the papilla, but in malignant cases, where the 
epithelial cellular masses have a strong tendency to penetrate the tissue deeply, these figures lie not solely at right angles, but often parallel or obliquely to the base line. In adenomata and warts the axes are at right angles always.

Eight months later pains returned at the eyebrow, where a palpable tumour appeared, headache came on, and a year later death from cancer of larynx.

Death from metastasis in such cases has not been often recorded. In Noyer's case the eye was excised for epibulbar epithelioma, and the patient later died of an intestinal affection. de Wecker's case had the eye removed for an epithelioma big enough to prevent closure of the lids; five-months after operation tumour reappeared in the orbit ; and six months later the patient died from an intermaxillary epitheliomatous metastasis. Robineau and Courserand's patient of 55 had an epibulbar epithelioma removed, and five months later parotid metastasis appeared, causing the death of the man after extirpation of the second tumour.

W. C. Souter.

\section{VIII.-RENAL RETINITIS}

Hanssen, R. and Knack, A. V. (Hamburg-Barmbeck). - On the question of renal retinitis. (Zur Frage der Retinitis nephritica.) Klin. Monatsbl. f. Augenheilk., SeptemberOctober, I9I7.

Hanssen and Knack, in a lengthy and diffuse paper accompanied by numerous tables and case histories, and illustrated by microphotographs, give an account of the cases of renal retinitis lately under observation in the Hamburg-Barmbeck general hospital. They have adopted the classification of Volhard and Fahr (Die Brightsche Nierenkrankheit, Berlin, 1914, Springer), in the arrangement of their cases; dividing them into three main groups :-

1. Primary degenerative, nèphrosis. 2. Primary inflammatory, nephritis. 3. Kidney affections in which vascular sclerosis is the prominent feature. A table giving the clinical symptoms characteristic of the three groups is attached.

The conclusions drawn by the authors occupy nine pages, largely filled with quotations from other well known authorities. In their opinion, albuminuric retinitis is mainly an inflammatory affection of the retina, frequently accompanied by a similar affection of the choroid. The suggestion of Leber and others, that the retinal aflection is caused by an ischaemia of the small blood-vessels is 
considered as opposed to all general pathology; such a condition never leading to the inflammatory changes described by the authors. In several of their cases, there was considerable disease of the interior of the eye with practically no change in the vessels.

Hanssen and Knack come to the conclusion that renal retinitis is due to more than one cause. They hold the impression strongly that the same poison works on parallel lines on the kidney and the eye. In other groups, the retinitis is directly dependent on the nephritis and due to interference with the retinal metabolism.

E. E. H.

\section{IX.-MISCELLANEOUS}

(I) von Skramlik (Freiburg i. Br.).-Argyrosis of the lacrymal sac. (Argyrose des Tränensackes.) Klin. Monatsbl. $f$. Augenheilk., April-May, 191 5, p. 443.

(1) von Skramlik's patient was suffering from corneal ulcer, and had used a 1 per cent. solution of colloidal silver regularly for three weeks, and occasionally during a year. A pronounced greyviolet discolouration of the whole conjunctiva resulted, mainly in the lower fornix. Chronic dacryocystitis was also present, and the lacrymal sac, on removal, was found to be similarly discoloured.

A careful description of the microscopical appearances is given, The deposit of silver was found to have produced two different sets of changes.

1. The subepithelial connective tissue was stained brown in varying degrees of intensity. This decoloration was diffuse, and not due to the deposit of granules of silver.

2. In addition to the diftuse staining, there were many granules, grey to black in colour, both in the superficial and the deeper parts of the wall of the sac. These granules were almost exclusively intracellular or deposited on elastic fibrils. Both the diffuse staining and the granules soon disappeared in the presence. of a 5 per cent: potassium cyanide solution. The author regards the diffuse staining as due to silver albuminate and the granules as metallic silver.

H. M. TRaQuair.

(2) Charles, J. W. (St. Louis). - Suspected teeth and the Wassermann reaction in the Missouri School for the Blind. Amer. Jl. of Ophthal., April, igi\%.

(2) Charles has already published (Amer. Jl. of Ophthal., March, 1917), under the title, "Dental stigmata of syphilis and transillumination in the demonstration of Hutchinson's teeth," the fact 
that among 106 pupils a certain number exhibited evidence of disturbed nutrition at the time of the laying down of the enamel, which had led to uneven or wavy lines in the enamel of the central incisors which could frequently best be seen by means of transillumination. Charles calls these "atypical Hutchinson's teeth," while the real Hutchinson's teeth are due to a total want of the enamel tubercles, resulting in the notching as well as narrowing of the incisal edge.

The dentist to the School for the Blind (Dr. Chase) has now selected all the pupils who exhibited any irregularities in the teeth, and all these have been subjected to the Wassermann test. Spinal puncture was only done in selected cases. We have here, then, eleven individuals of ages ranging up to 21 years, all of whom have suffered from severe eye disease and all of whom present some dental irregularity. Of these eleven, seven presented a negative Wassermann and four were positive. The author concludes: "When one considers the statistics of syphilographers, we find the proportion of positives sufficiently high to make these teeth significant as indices, although not pathognomonic."

ERnest Thomson.

(3) Weve, U.-The light-sense of the larvae of calliphora erythrocephala (meat fly?). (De licht-zin der larven van calliphora erythrocephala [vleesch-vlieg] ?) Nederlandsch Tijdschrift voor Geneeskunde, I9I6, Part i, p. I 95.

(3) The larvae of this fly move away from a source of light. Weve measured their sensibility to light of different colours, and found that their sensibility was strikingly conformable to that of colourblind people. They possess a well-developed adaptation to light. The organs to which the sensibility to light is due are situated in the first or head segment. For description of the methods used, see the original. (Weve's article appeared also in German in Zeitschrift für Sinnesphysiologie, Bd. XLIX).

G. F. Rochat.

(4) Henkes, T. C.-A case of gangrenous inflammation of the frontal sinus, with purulent disease of the ethmoidal cells, and perforations in the orbit. (Een geval van gangreneuse ontsteking van den voorhoofds boezem en etterige ontsteking der zeefbeen cellen, met doorbraak naar den oogkuil.) Nederlandsch Tijdschrift voor Geneeskunde, I916, Part i, p. 2379.

(4) Notwithstanding the extremely severe disease of the frontal and ethmoidal sinuses, the patient had never before complained of headache. After the operation, in which the trochlea and the lamina papyracea had been totally removed, the eye movements were quite normal.

G. F. Rochat. 
(5) Gallenga, Dr. Prof. C. (Parma). - Vascular changes in pterygium. (Le alterazione vasali nello pterigio.) Arch. di Ottal., March-May, 1918.

(5) Gallenga gives a brief summary of the vascular changes he has found in the various kinds of pterygium. His statement is as follows :

"The vascular alterations in pterygium consist in a slow and progressive fibrous and hyaline degeneration of the vessel walls resulting in contraction and obliteration of the lumen of vessels and capillaries; accompanied by obliteration of the lymphatic vessels of the body of the pterygium with a corresponding considerable dilatation of those of the basal part, resulting in the formation of large lymphatic spaces from distension of the more conspicuous lymphatic trunks of the superficial and deep rete.

These alterations in the blood and lymphatic vessels are accompanied pari passu by diffusion and extension of the hyaline degeneration into the connective tissue stroma, and by alterations of the corneal surface especially aflecting Bowman's membrane.

The disturbances of circulation and nutrition that result assist the diffusion of the degenerative processes in the conjunctiva which forms the pterygium.

The frequency then of the dilatations of the lymphatic vessels in the base of the pterygium, together with the obliteration of the lymphatic branches in the proximal portion of the apex, may give rise to the formation of some of the cysts previously described."

E. E. H.

(6). Hardy, William F. (St. Louis).-Renal choked disc. Amer Jl. of Ophthal., December, I916.

(6) The article, by Hardy, which he entitles "Renal choked disc," is one of a type which somehow appears to be fairly common with American writers, in which a very large number of distinct statements is made within a short compass. Such articles, however intellectually nutritive they may be, and this is one of that character, almost defy the power of a précis writer to reduce them to shorter form. The present reviewer will not attempt the task, but at the same time it is right that he should reproduce the following statements by the author, as indicating the lines upon which the latter goes. - "The contentions embodied in this paper, and made a prelude to the direct discussion of renal choked disc, are (1) that optic neuritis and choked disc are aetiologically distinct entities; (2) that the assumption of a manifold pathogenesis of choked disc is probably incorrect; (3) that papilloedema is primarily of mechanical origin, all the concomitant phenomena being accountable for on that basis ; (4) that the inability 
to always clinically distinguish between the two conditions does not necessarily imply a common origin or identical process; $(5)$ that optic neuritis is primarily and essentially an inflammatory process; choked disc is primarily and essentially an oedema and lymph stasis, the resultant of increased intracranial tension; (6) renal choked disc exemplifies both processes, each with its separate pathogenesis, showing a lymph stasis with oedema and also pathological changes." The reviewer thinks that it would be impossible for him to present the author's paper in brief any better than is done in these introductory words by the author himself.

ERNEST THOMSON.

(7) Hardy, William F. and Lamb, H. D. (St. Louis).-Essential shrinking of the conjunctiva with a report of two cases. Amer. Jl. of Ophthal., October, 1917.

(7) Hardy and Lamb give a very full bibliography of the literature of ocular pemphigus and what has been called " essential shrinking" of the conjunctiva. They show that pemphigus of the eye occurs statistically once in 20,000 eye cases. Pergens divided the cases into four groups. (1) Those with vesicles on the skin and finally on the mucous membrane. (2) Cases without vesicles on the skin, but with them on the mucous membrane. (3) Cases in which vesicles were seen only on the eye. (4) Those cases in which no vesicles whatever are found. These last are the real cases of "essential shinking." The authors ofter a classification of their own, as follows, namely: (1) Those cases with skin lesions or blebs on mucous membranes other than those of the eye. (2) Those associated with syphilitic pemphigus or syphilitic conjunctivitis. Those with no antecedent history of skin or mucous membrane involvement. These last are cases of "essential shrinking." The authors hold, with Adam, that the conjunctival shrinking, following pemphigus, is not " essential" shrinking, but is a cicatrization of the subepithelial and adenoid layer of the conjunctiva. The term " essential shrinking," is more strictly applicable to the slow chronic process which characterizes the disease without antecedent pemphigus. The two cases reported by Hardy and Lamb themselves appear to have followed pemphigus. The bibliography contains seventy-six references and will be of value to other writers.

ERNEST THOMSON. 